\title{
Trends in the Use of Evidence-based Therapies Early in the Course of Acute Myocardial Infarction and its Influence on Short Term Patient Outcomes
}

\author{
Mohammad Al-Jarallah ${ }^{1, *}$, Mouaz H. Al-Mallah ${ }^{2}$, Mohammad Zubaid ${ }^{3}$, Alawi A. Alsheikh-Ali ${ }^{4}$, \\ Wafa Rashed ${ }^{5}$, Mustafa Ridha ${ }^{6}$, Fahad Alenizi ${ }^{7}$, Bassam Bulbanat ${ }^{1}$, Mousa Akbar ${ }^{8}$, \\ Rashed Al-Hamdan ${ }^{9}$ and Shahid Zubair ${ }^{10}$
}

${ }^{1}$ Division of Cardiology, Al-Amiri Hospital, Kuwait

${ }^{2}$ King Abdul-Aziz Cardiac Center, Riyadh, KSA

${ }^{3}$ Department of Medicine, Faculty of Medicine, Kuwait University, Kuwait

${ }^{4}$ Institute of Cardiac Sciences, Sheikh Khalifa Medical City, Abu Dhabi, United Arab Emirates and Tufts Clinical and Translational Science Institute, Tufts University School of Medicine, Boston, MA, USA

${ }^{5}$ Division of Cardiology, Mubarak Alkabeer Hospital, Kuwait

${ }^{6}$ Division of Cardiology, Aladan Hospital, Kuwait

${ }^{7}$ Division of Cardiology, Alfarwaniya Hospital, Kuwait

${ }^{8}$ Division of Cardiology, Alsabah Hospital, Kuwait

${ }^{9}$ Division of Cardiology, Aljahra Hospital, Kuwait

${ }^{10}$ Department of Medicine, Kuwait Oil Company Hospital, Kuwait

\begin{abstract}
Aim: To evaluate changes in management practices and its influence on short term hospital outcomes in patients with acute myocardial infarction (AMI) admitted during two different time periods, 2007 and 2004.

Methods and Results: We studied AMI patients from two acute coronary syndrome registries carried out in Kuwait in 2007 and 2004. We included 1872 and 1197 patients from the 2007 and 2004 registries, respectively. When compared with 2004, patients from the 2007 registry had similar baseline clinical characteristics. In 2007 compared to 2004, during the in-hospital period, patients with AMI received significantly more statins ( $94 \%$ vs. $73 \% \%, p<0.0001)$, Angiotensin converting enzyme (ACE) inhibitors and angiotensin receptor blockers (ARB) (70\% vs. 47\%, p<0.001), and Clopidogrel ( $38 \%$ vs. $4 \%, p<0.001)$, while beta-blockers use dropped in 2007 compared to 2004 (63\% vs. 68\%, p=0.0066). The rates of in-hospital mortality and recurrent ischemia were significantly lower in the 2007 cohort compared with the 2004 cohort (for mortality $2.2 \%$ vs. $3.9 \%, \mathrm{P}=0.0008$, for recurrent ischemia $13.7 \%$ vs. $20.4 \%, \mathrm{P}=0<0.0001$ ). Higher utilization of angiotensin converting enzyme inhibitors, angiotensin receptor blockers and statins were the main contributors to the improved in-hospital mortality and morbidity.

In Conclusion: In the acute management of AMI, there was a significant increase in the use of statins, ACE inhibitors and Clopidogrel in 2007 compared to 2004. This was associated with a significant decrease in the in-hospital mortality and recurrent ischemia. Adherence to guidelines recommended therapies improved in-hospital outcomes.
\end{abstract}

Keywords: Acute Coronary Syndrome, Outcomes, Evidence based therapies.

\section{INTRODUCTION}

Guidelines for the management of patients with acute coronary syndromes (ACS) recommend interventional and pharmacologic strategies that are proven to improve patient outcomes [1-3]. However, studies have documented substantial gaps between guideline recommendations and clinical

\footnotetext{
*Address correspondence to this author at the Aramex House, Old Bath Road, Colnbrook, Slough, Berkshire SL3 0NS, KWI 16262, UK; Tel: (965) 97444566; Fax: (965) 225111108; E-mail: dmaj21@hotmail.com
}

practice [4, 5]. Large multinational registries that reflect unselected, non-biased patient management and outcomes have shown that adoption of guidelines into routine practice is suboptimal and suffers from significant geographical and temporal variations [6]. The suboptimal use of guideline-recommended therapies include underutilization of reperfusion in ST-segment elevation myocardial infarction (STEMI), [4] and the suboptimal prescription of statins, Clopidogrel and angiotensin converting enzyme (ACE) inhibitors $[4,6,7]$. 
In Kuwait, several registries were carried out to study unselected cases of ACS [8-11]. Some of these registries have demonstrated suboptimal use of certain proven therapies early in the course of ACS, like ACE inhibitors, statins, antiplatelets and interventional procedures [8]. However, the extent to which this has changed over time and whether such changes are associated with improved outcomes is unknown. In the present analysis, we describe temporal changes in the utilization of evidence-based therapies early in the course of acute myocardial infarction (AMI), and the association between such changes and short term patient outcomes, utilizing prospectively-collected data from two registries of ACS with similar study protocols conducted in two different time intervals (2004 and 2007).

\section{METHODS}

The present study had four specific aims: 1) describe and compare the baseline characteristics of patients with AMI in two different time-periods (2007 versus 2004), 2) describe temporal trends in the utilization of evidence-based therapies early in the course of AMI in 2007 compared to 2004, 3) evaluate whether there has been significant improvement in short term hospital outcomes among patients with AMI in 2007 compared to 2004, and 4) assess whether the temporal trends in short term patient outcomes are attributed to changes in the early utilization of evidence-based therapies. To address these aims, we used data from two cohorts of patients with AMI enrolled in two separate ACS registries; patients enrolled from Kuwait during the Gulf Registry of Acute Coronary Events (Gulf RACE), carried out in May 2006 and from January to June 2007, and patients enrolled in the single-country Kuwait acute coronary syndrome (KACS) registry, carried out from December 2003 to May 2004. The methods of each registry have been previously published $[8,10]$.

Ethics approval was obtained for both registries from the country's ethics approval committee. The two had similar study protocols and included consecutive patients admitted to the 7 general hospitals in Kuwait with the diagnosis of ACS. This included unstable angina, non-ST-segment elevation myocardial infarction (NSTEMI) and STEMI. KACS registry was carried out in Kuwait only, while Gulf RACE was a multinational registry carried out in 6 Gulf countries including Kuwait. Similar Kuwait-based hospitals participated in KACS registry and Gulf RACE. These hospitals were Mubarak Al-Kabeer, Al-Amiri, AlAdan, Al-Farwaniya, Al-Jahra, Al-Sabah and Kuwait Oil Company. At each hospital, designated physicians prospectively identified consecutive patients admitted with ACS over a period of 6 months. Similar structured data collection forms were used for both registries and were completed during hospitalization.

Diagnosis of the different types of ACS and definitions of data variables were based on the American College of Cardiology (ACC) clinical data standards [11]. Myocardial infarction was defined as typical rise and gradual fall of biochemical markers of myocardial necrosis with at least one of the following (1.Ischemic symptoms, 2.Development of pathological Q waves on the ECG, 3. ECG changes suggestive of ischemia (ST-segment elevation or depression).
Cardiac biomarkers were measured locally at each hospital laboratory, using its own assays and reference ranges. Shortfall was defined as the proportion of patients with STEMI who did not receive reperfusion therapy despite presenting within 12 hours of symptom onset in the absence of contraindications to reperfusion therapy.

In both registries, patient treatment and management was left to the discretion of the treating physician. The present study included data from the AMI populations from both registries to compare the treatments they received and their hospital outcomes. The primary outcome of this analysis was all cause in-hospital mortality. Secondary outcomes included in-hospital recurrent ischemia, recurrent myocardial infarction, heart failure, cardiogenic shock and major bleeding.

\section{STATISTICAL ANALYSIS}

Baseline demographics, and clinical and presentation characteristics were described and compared between the two cohorts (2007 versus 2004) using standard descriptive and comparative statistics. Categorical variables are presented as number of cases and percentage and compared using the Chi-square test or Fisher's exact test as appropriate. Continuous variables are presented as mean \pm standard deviation or median $\left[25^{\text {th }}-75^{\text {th }}\right.$ percentiles] for non-normally distributed variables, and compared using independent t-test or the non-parametric Mann-Whitney test as appropriate.

To compare the utilization of evidence-based therapies and in-hospital outcomes in the two cohorts while accounting for difference in baseline characteristics, we used a propensity score methodology. A propensity score for being in the 2004 cohort was calculated using logistic regression with inclusion in the 2004 cohort as the dependent variable and all measured baseline clinical characteristics as independent variables.

To assess the effect of evidence-based therapies on in-hospital death we compared the impact of cohort (2007 versus 2004) in logistic regression models adjusted for the strata of the propensity score with or without including treatment variables in the model. All tests were two-sided, and a P-value 0.05 was considered significant. All analyses were performed with SAS version.

\section{RESULTS \\ Baseline Patient Characteristics}

There were 1,197 AMI patients in the 2004 cohort registry and 1,872 patients in the 2007 cohort. The two cohorts were generally similar in their baseline characteristics with regard to age, history of diabetes mellitus, and prior coronary artery bypass graft surgery. The 2007 cohort included more females, and was more likely to have a history of hypertension, dyslipidemia, coronary artery disease, prior MI or percutaneous coronary revascularization (Table 1). Differences in presentation characteristics were also noted, including lower utilization of ambulance services in 2007 and a smaller proportion of patients with STEMI. Inpatient angiography rates were similarly low in both cohorts, and most patients were managed in an acute care setting. 
Temporal Trends in the Early Use of Evidence-Based Therapies

There were significant differences in the early in-hospital use of evidence-based therapies in 2007 compared to 2004
(Table 2, Fig. 1). The rate of aspirin use was equally high in both cohorts. Compared to 2004, patients with AMI in 2007 were significantly more likely to receive Clopidogrel $(38 \%$ vs. $4 \%, \mathrm{p}<0.0001)$, statins $(94 \%$ vs. $73 \%, \mathrm{p}<0.0001)$, ACE inhibitors or angiotensin receptor blockers (ARB) (70\% vs.

Table 1. Clinical Characteristics of Patients Hospitalized with Acute Myocardial Infarction in 2004 and 2007

\begin{tabular}{|c|c|c|c|}
\hline & $\begin{array}{c}2004 \\
N=1197\end{array}$ & $\begin{array}{c}2007 \\
N=1872\end{array}$ & P-value \\
\hline Age (mean \pm SD) & $55 \pm 13$ & $55 \pm 13$ & 0.91 \\
\hline Male gender & $980(82 \%)$ & $1460(78 \%)$ & 0.0090 \\
\hline Diabetes & $547(46 \%)$ & $899(48 \%)$ & 0.22 \\
\hline Hypertension & $493(41 \%)$ & $947(51 \%)$ & $<0.0001$ \\
\hline Current smoking & $538(45 \%)$ & $759(41 \%)$ & 0.0016 \\
\hline Family history & $172(14 \%)$ & $225(12 \%)$ & 0.06 \\
\hline Hyperlipidemia & $318(27 \%)$ & $594(32 \%)$ & 0.0024 \\
\hline Prior CAD & $318(27 \%)$ & $621(33 \%)$ & $<0.0001$ \\
\hline Past history of MI & $288(24 \%)$ & $560(29.9 \%)$ & $<0.0001$ \\
\hline Past history of PCI & $79(6.6 \%)$ & $249(13.3 \%)$ & $<0.0001$ \\
\hline Past history of CABG & $57(4.8 \%)$ & $106(5.7 \%)$ & 0.28 \\
\hline Heart rate & $85 \pm 23$ & $86 \pm 24$ & 0.57 \\
\hline Systolic BP & $139 \pm 31$ & $142 \pm 31$ & 0.01 \\
\hline Systolic $\mathrm{BP}<90$ & $46(3.8 \%)$ & $39(2.1 \%)$ & 0.0046 \\
\hline Serum creatinine & $107 \pm 83$ & $89 \pm 75$ & $<0.0001$ \\
\hline Peak troponin & $26 \pm 42$ & $26 \pm 57$ & 0.98 \\
\hline Use of ambulance & $127(11 \%)$ & $125(7 \%)$ & $<0.0001$ \\
\hline In-hospital Angiography & $222(19 \%)$ & $330(18 \%)$ & 0.53 \\
\hline $\begin{array}{l}\text { Discharge Diagnosis } \\
\text { STEMI } \\
\text { NSTEMI }\end{array}$ & $\begin{array}{l}673(56 \%) \\
524(44 \%)\end{array}$ & $\begin{array}{c}724(39 \%) \\
1148(61 \%)\end{array}$ & $<0.0001$ \\
\hline
\end{tabular}

MI, myocardial infarction; PCI, percutaneous coronary intervention; CABG, coronary, coronary artery bypass grafting; BP, blood pressure ECG, electrocardiogram and ICU, intensive care unit.

Table 2. Rate of Utilization of Pharmacological Therapies in Patients with Acute Myocardial Infarction in 2004 and 2007

\begin{tabular}{|l|c|c|c|}
\hline & $\begin{array}{c}\mathbf{2 0 0 4} \\
\mathbf{N = 1 1 9 7}\end{array}$ & $\begin{array}{c}\mathbf{2 0 0 7} \\
\mathbf{N = 1 8 7 2}\end{array}$ & $\mathbf{P - v a l u e ~}$ \\
\hline \hline Aspirin & $1165(97 \%)$ & $1836(98 \%)$ & $<.17$ \\
\hline Clopidogrel & $48(4 \%)$ & $702(38 \%)$ & $<0.0001$ \\
\hline LMWH & $95(8 \%)$ & $537(29 \%)$ & $<0.0001$ \\
\hline UFH & $1061(89 \%)$ & $1298(69 \%)$ & 0.0001 \\
\hline Beta-Blocker & $815(68 \%)$ & $1184(63 \%)$ & $<0.0001$ \\
\hline ACE-I or ARB & $566(47 \%)$ & $1312(70 \%)$ & $<0.0001$ \\
\hline Statin & $869(73 \%)$ & $1768(94 \%)$ & 0.006 \\
\hline Diuretics & $250(21 \%)$ & $472(25 \%)$ & $<$ \\
\hline
\end{tabular}

LMWH, Low molecular weight heparin; UFH, unfractionated heparin; ACE-I, angiotensin converting enzyme inhibitor; ARB, angiotensin receptor blocker. 
$47 \%, \mathrm{p}<0.0001)$, and low molecular weight heparin (LMWH) $(29 \%$ vs. $8 \%, \mathrm{p}<0.0001)$. The use of beta-blockers declined from $68 \%$ in 2004 to $63 \%$ in 2007 ( $\mathrm{p}=0.0066$ ). The significant differences in early utilization of evidence-based therapies in the two time-periods persisted after adjusting for the strata of the propensity score (Fig. 1).

\begin{tabular}{lc} 
Medication & Odds ratio $(95 \% \mathrm{Cl})$ \\
\cline { 2 - 2 } $\begin{array}{l}\text { Aspirin } \\
\text { Aspirin (adjusted) }\end{array}$ & $1.1(0.37-3.1)$ \\
Clopidogril & $28.8(16.8-49.5)$ \\
Clopidogril (adjusted) & $27.5(16.1-46.8)$ \\
NV Heparin & \\
N Heparin (adjusted) & $0.43(0.30-0.61)$ \\
& $0.40(0.31-0.62)$ \\
LMWH & $3.5(2.3-5.3)$ \\
LMWH (adjusted) & $3.4(2.3-5.1)$ \\
ACEl or ARB & \\
ACEl or ARB (adjusted) & $2.7(2.2-3.3)$ \\
& \\
Beta Blockers & \\
Beta Blockers (adjusted) & $0.73(0.58-0.92)$ \\
Statin & $9.4(6.3-14.0)$ \\
Statin (adjusted) & $8.3(5.7-1.1)$ \\
\hline
\end{tabular}

0.1
Among patients with STEMI (Table 3), thrombolytic therapy was the sole mode of reperfusion and most patients who were candidates for thrombolytic therapy were similarly likely to receive it in both cohorts (short fall $7.8 \%$ in 2007 versus $6.1 \%$ in $2004, \mathrm{P}=0.28$ ). The median time from first diagnostic electrocardiogram (ECG) to administration of

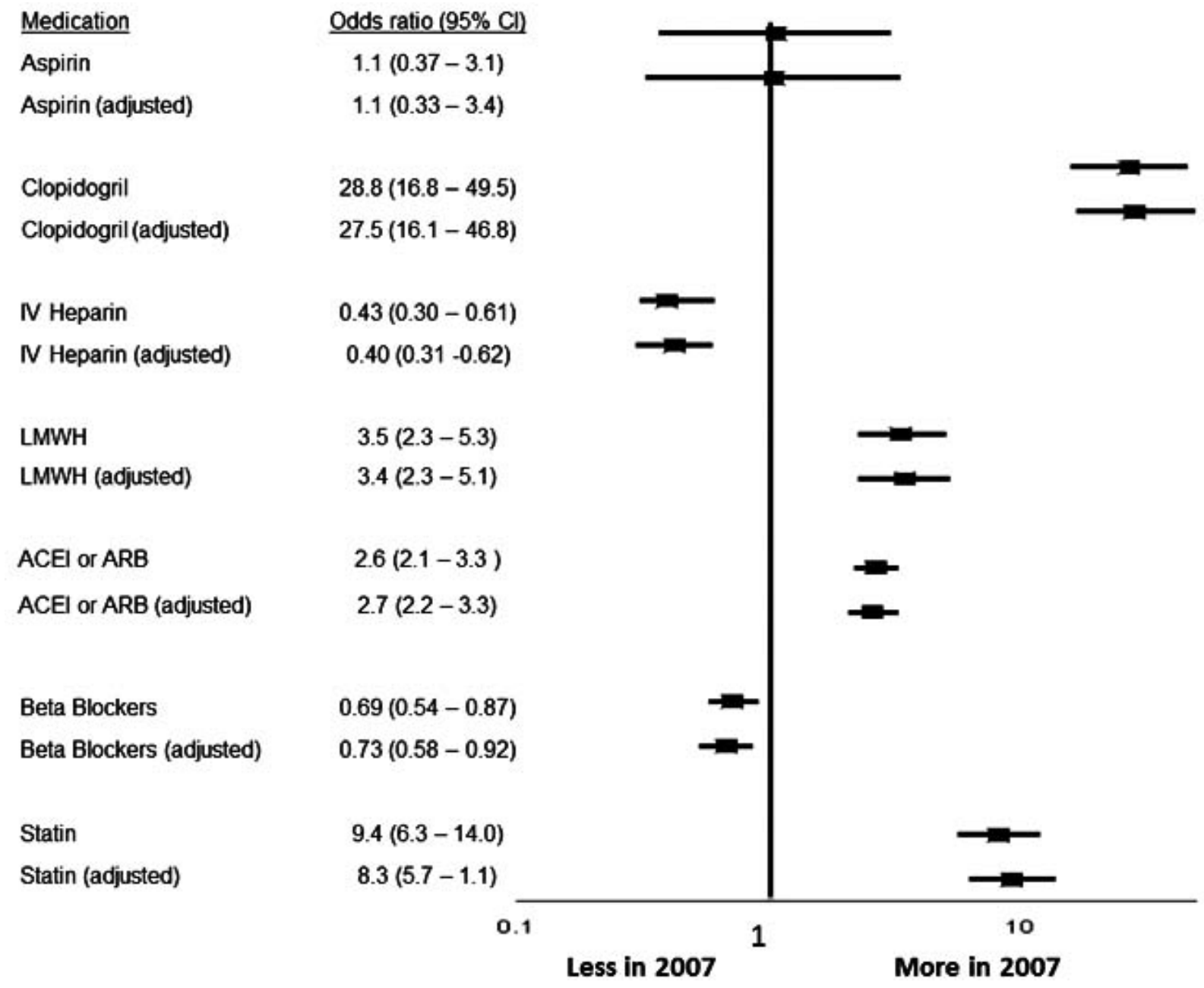

Fig. (1). Odds ratios of utilizing evidence-based therapies between 2004 and 2007 with and without adjustment with the propensity score.

Table 3. Clinical Variables and Type of Thrombolytic Used in the ST Segment Elevation Myocardial Infarction (STEMI) Population in 2004 and 2007

\begin{tabular}{|l|c|c|c|}
\hline & $\begin{array}{c}\mathbf{2 0 0 4} \\
\mathbf{N = 6 7 3}\end{array}$ & $\mathbf{2 0 0 7}$ \\
$\mathbf{N = 7 2 4}$ & & \\
\hline Type of Thrombolytic & & $6(1.0 \%)$ \\
tPA & $10(1.8 \%)$ & $1(0.2 \%)$ & 0.0008 \\
SK & $14(2.5 \%)$ & $301(53.2 \%)$ & $258(45.6 \%)$ \\
Reteplase & $254(45.9 \%)$ & $29(16-50)$ & $<0.0001$ \\
TNK & $276(49.8 \%)$ & $47 / 611(7.8 \%)$ & 0.28 \\
\hline Diagnostic ECG to Thrombolysis time (Median, IQ) & $38(24-60)$ & $105(14.5 \%)$ & 0.033 \\
\hline Shortfall & $36 / 590(6.1 \%)$ & $72(10.7 \%)$ & \\
\hline Delayed Presentation & & \\
\hline
\end{tabular}

tPA, tissue plasminogen activator; SK,Strptokinase; TNK, Tenecteplase. Shortfall is defined as the patients presenting with STEMI within 12 hours of symptom onset in the absence of contraindication to thrombolytic therapy and did not receive it. 
thrombolytic therapy shortened significantly in 2007 compared to 2004 ( 29 minutes vs. 38 minutes, $\mathrm{p}<0.0001$ ).

\section{Temporal Trends in Short Term Patient Outcomes}

Table 4 displays the crude in-hospital outcome rates for the two time-periods. In univariate analysis, there was a significant decrease in in-hospital mortality $(2.2 \%$ vs. $3.9 \%$, $\mathrm{P}<0.001)$ as well as recurrent ischemia (13.7\% vs. $20.4 \%$,
$\mathrm{P}<0.0001$ ) in 2007 compared to 2004 and a non-significantly lower rate of recurrent MI favoring 2007 (2.2\% vs. 3.3\%, $\mathrm{P}=0.08$ ). There were no significant differences in the rates of other in-hospital outcomes including heart failure, cardiogenic shock, stroke, or major bleeding.

Multivariable analysis was performed to determine the impact of early pharmacologic interventions on all-cause mortality (Fig. 2). The unadjusted odds ratio (OR) showed

Table 4. In-Hospital Outcomes of Patients with Acute Myocardial Infarction in 2004 and 2007

\begin{tabular}{|l|c|c|c|}
\hline & $\begin{array}{c}\mathbf{2 0 0 4} \\
\mathbf{N = 1 1 9 7}\end{array}$ & $\begin{array}{c}\mathbf{2 0 0 7} \\
\mathbf{N = 1 8 7 2}\end{array}$ & P-value \\
\hline \hline Death & $47(3.9 \%)$ & $42(2.2 \%)$ & 0.0008 \\
\hline Recurrent ischemia & $244(20.4 \%)$ & $257(13.7 \%)$ & 0.08 \\
\hline Recurrent MI & $39(3.3 \%)$ & $41(2.2 \%)$ & 0.23 \\
\hline Heart Failure & $130(10.9 \%)$ & $231(12.3 \%)$ & 0.84 \\
\hline Cardiogenic shock & $43(3.6 \%)$ & $64(3.4 \%)$ & 0.93 \\
\hline Stroke & $3(0.25 \%)$ & $5(0.27 \%)$ & 0.24 \\
\hline Major bleed & $10(0.8 \%)$ & $9(0.4 \%)$ & 0.0037 \\
\hline Death or MI & $81(6.8 \%)$ & $81(4.3 \%)$ & $<0.0001$ \\
\hline Death or MI or ischemia & $284(23.7 \%)$ & $189(15.3 \%)$ & \\
\hline
\end{tabular}

\section{Medication}

Unadjusted

Adjusted for Beta Blockers

Adjusted for ACEI or ARB

Adjusted for LMWH

Adjusted for Clopidogril

Adjusted for Statin

Adjusted for ACEl or ARB and statin

Adjusted for ACEl or ARB, Statin and LMWH

Adjusted for ACEl or ARB, Statin, LMWH and Clopidogril

Adjusted for Adjusted for ACEI or ARB, Statin, LMWH, Clopidogriland beta blockers

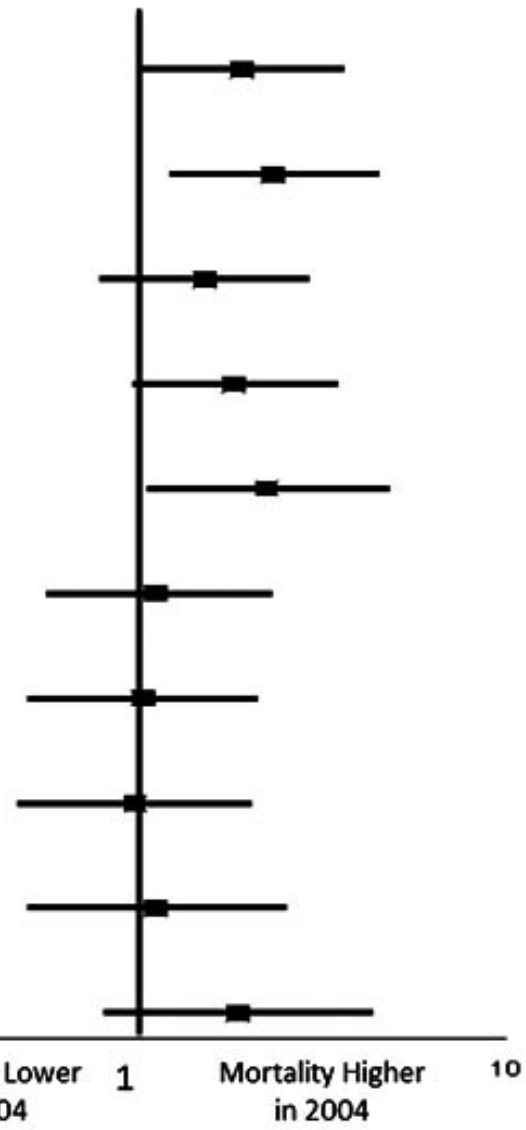

Fig. (2). Effects of utilizing evidence-based therapies on 2004 mortality after adjustment for the propensity score. 
an increased mortality in 2004 (1.8 [1.2-2.7]). Adjusting for ACE inhibitors or ARB as well as adjusting for statin therapy neutralized the difference between the two cohorts. Adjusting for different combination of medications is also shown in Fig. (2). The decreased utilization of beta blockers, on the other hand, had offset some of the beneficial effects of statins and ACE inhibitors.

Similar modeling was repeated after adjusting for the propensity score (Fig. 3). Before adjustment, the model suggested that patients admitted in 2004 had $80 \%$ higher likelihood of in-hospital mortality compared to 2007 (OR 1.8). This continued to be significant after adjusting for the propensity score. A model adjusting for all therapies and the propensity score showed that there were no significant differences in mortality between the two cohorts. This was especially true when adjustment was only done for ACEI/ ARBs and statins.

\section{DISCUSSION}

We examined our practice to find out the extent to which cardiologists in Kuwait have improved their early management of AMI and the influence of such change on short term patients outcomes. We have demonstrated two important findings. First, the early management of AMI in this part of the Middle East has changed to the better. Second, this change has resulted in significant improvement in short term outcomes of mortality and recurrent ischemia. This improvement in practice involved shorter diagnostic ECG to needle time (in patients with STEMI) and higher rates of utilization of ACE inhibitors and statins, as well as better use of other proven therapies like Clopidogrel and low molecular weight heparin.

The last two decades have witnessed advances in the management of AMI at the interventional and pharmacotherapy levels [12-26]. The influence of these changes on outcome is well documented in several large trials [26-39]. The additive effects of these interventions can lead to an $80 \%$ reduction in adverse events [40]. These advances have resulted in the formation of guidelines that address the proper treatment and management of patients with AMI $[2,3]$. Data show that physicians do not embrace guidelines immediately and, as a result, a gap exists between recommendations and implementation [4-6].

We did observe a significant improvement of in-hospital outcomes including lower in-hospital mortality and recurrent ischemia. This better outcome was despite the fact that the characteristics and risk status of AMI patients at presentation suggested that the 2007 group was a higher risk population due to the inclusion of more patients with hypertension, previous percutaneous coronary interventions and myocardial infarction. In an attempt to understand the reasons behind this improvement in short term outcomes, we carried out further analysis taking into account the different therapies that were provided. Our analysis demonstrated increased utilization of multiple drugs that were shown to reduce adverse cardiovascular outcomes in patients with ACS. Despite this improvement in practice, the rates of utilization of some of these drugs are still below the current standard when compared to other larger multinational registries [5]. For example, the rate of utilization of beta-blockers and

\begin{tabular}{|c|c|}
\hline Model & Odd Ratio \\
\hline Unadjusted & $1.8(1.2-2.7)$ \\
\hline $\begin{array}{l}\text { Adjusted for } \\
\text { propensity }\end{array}$ & $1.6(1.03-2.4)$ \\
\hline $\begin{array}{l}\text { Adjusted for } \\
\text { propensity and } \\
\text { medications }\end{array}$ & $1.5(0.9-2.5)$ \\
\hline $\begin{array}{l}\text { Adjusted for } \\
\text { propensity and } \\
\text { medications } \\
\text { (except beta } \\
\text { blockers) }\end{array}$ & $1.1(0.6-1.6)$ \\
\hline
\end{tabular}

Model c-index

0.571

0.602

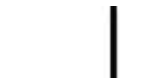

Fig. (3). Effects of utilizing evidence-based therapies on 2004 mortality after adjustment for the propensity score. 
Clopidogrel is low in our registry compared to the Grace registry.

Our understanding of the pathophysiology of atherosclerosis and the mechanisms of myocardial infarction has evolved over the last few decades. Multiple randomized control trials have suggested that some drugs have a significant role in lowering early cardiovascular mortality when used in the acute phase $[26,32,37,38]$. In particular, in the Fourth International Study of Infarct Survival (ISIS-4) trial, the effect of ACE inhibitor on mortality was demonstrated as early the first 24 hours of the treatment initiation and persisted up to one year [37]. In pravastatin or atorvastatin evaluation and infarction therapy (PROVE-IT trial), high dose statin reduced mortality with a benefit that was apparent within the first 30 days of treatment initiation [38]. Our findings that statins and ACE inhibitors were the major contributors to the decreased in-hospital mortality in 2007 compared to 2004 is in keeping with the published literature. It is also conceivable that more frequent use of statins and ACE inhibitors are markers of other processes of care that were not measured but had a favorable effect on short term outcomes.

\section{STRENGTHS AND LIMITATIONS}

The data we presented were derived from all consecutive AMI patients admitted to all hospitals in Kuwait during the two different study periods. While selection bias cannot be excluded, we believe our sample represents the practice of AMI management during those times. To our knowledge, this study is the first from the Arab world and Gulf region that looks at changes in the early management of AMI patients and its influence on short term outcomes. Our findings are limited by the fact that we were not able to adjust for other important variables such as ejection fraction and angiographic severity of coronary artery disease. Also, the observational nature of the study precludes us from inferring cause-and-effect associations between treatment patterns and in-hospital outcomes but it is highly plausible that the changes in clinical outcomes are the direct consequence of changes in practice.

\section{CONCLUSIONS AND IMPLICATIONS}

Our analysis demonstrated a significant favorable change towards the adoption of guidelines-recommended therapies in patients admitted with AMI. This change was associated with a lower in-hospital mortality and recurrent ischemia. These data provide a strong argument in favor of continued educational efforts to increase the adoption of guidelines in the management of patients with AMI.

A significant effort needs to be made to educate providers (both physicians and nurses), identify barriers, and assemble a multidisciplinary team that would be able to impact the process of care in the coronary care units. The use of standardized myocardial infarction admission and discharge orders and care pathways may help to increase the implementation of guidelines-recommended therapies in the care of AMI patients.

\section{REFERENCES}

[1] Mukherjee D, Fang J, Chetcuti S, Moscucci M, Kline-Rogers E, Eagle KA. Impact of combination evidence-based medical therapy on mortality in patients with acute coronary syndromes. Circulation 2004; 109: 745-9.

[2] Antman EM, Anbe DT, Armstrong PW, et al. ACC/AHA guidelines for the management of patients with ST-elevation myocardial infarction; A report of the American College of Cardiology/American Heart Association Task Force on Practice Guidelines (Committee to Revise the 1999 Guidelines for the Management of patients with acute myocardial infarction). J Am Coll Cardiol 2004; 44: E1-E211.

[3] Anderson JF, Adams CD, Antman EM, et al. ACC/AHA 2007 Guidelines for the Management of Patients with Unstable Angina/Non-ST-Elevation Myocardial Infarction. J Am Coll Cardiol 2007; 50: 652-726.

[4] Eagle KA, Goodman SG, Avezum A, Budaj A, Sullivan CM, Lop Sendon J. Practice variation and missed opportunities for reperfusion in ST segment elevation myocardial infarction: findings from the Global Registry of Acute Coronary Events (GRACE). Lancet 2002; 359: 373-7.

[5] Carruthers KF, Dabbous OH, Flather MD, et al. The Global Registry of Acute Coronary Events (GRACE). Contemporary management of acute coronary syndromes: does the practice match the evidence? Heart 2005; 91: 290-8.

[6] Fox KA, Goodman SG, Anderson FA Jr, et al., on behalf of the GRACE investigators. From guidelines to clinical practice: the impact of hospital and geographical characteristics on temporal trends in the management of acute coronary syndromes. The Global Registry of Acute Coronary Events (GRACE). Eur Heart 2003; 24: 1414-24.

[7] Gandjour A, Kleinschmit F, Lauterbach KW. European comparison of costs and quality in the treatment of acute myocardial infarction (2000-2001). Eur Heart J 2002; 23: 858-68.

[8] Zubaid M, Rashed WA, Husain M, et al. A registry of acute myocardial infarction in Kuwait: patient characteristics and practice patterns. Can J Cardiol 2004; 20: 783-7.

[9] Rashed W, Zubaid M, David T, et al. Patient characteristics and practice patterns in the treatment of acute myocardial infraction in Kuwait: a pilot study. Med Princ Pract 2002; 11: 196-201.

[10] Zubaid M, Rashed W, AlKhaja N, et al. Clinical presentation and outcomes of acute coronary syndromes in the Gulf Registry of Acute Coronary Events (Gulf RACE). Saudi Med J 2008; 29: 251-5.

[11] Cannon CP, Battler A, Brindis RG, et at. American College of Cardiology key data elements and definitions for measuring the clinical management and outcomes of patients with acute coronary syndromes. A report of the American College of Cardiology Task Force on Clinical Data Standards (Acute Coronary Syndromes Writing Committee). J Am Coll Cardiol 2001; 38: 2114-30.

[12] ISIS-2 (Second International Study of Infarct Survival) Collaborative Group. Randomised trial of intravenous streptokinase, oral aspirin, both, or neither among 17,187 cases of suspected acute myocardial infarction: ISIS-2. Lancet 1988; 2: 349-60.

[13] The GUSTO investigators. An international randomized trial comparing four thrombolytic strategies for acute myocardial infarction. N Engl J Med 1993; 329: 673-82.

[14] The Global Use of Strategies to Open Occluded Coronary Arteries (GUSTO III) Investigators. A comparison of reteplase with alteplase for acute myocardial infarction. N Engl J Med 1997; 337: 1118-23.

[15] Bonnefoy E, Lapostolle F, Leizorovicz A, et al., for the Comparison of Angioplasty and Prehospital Thrombolysis in Acute Myocardial Infarction Study Group. Primary angioplasty versus prehospital fibrinolysis in acute myocardial infarction: a randomised study. Lancet 2002; 360: 825-9.

[16] Steg PG, Bonnefoy E, Chabaud S, et al. Impact of Time to Treatment on Mortality After Prehospital Fibrinolysis or Primary Angioplasty: data from the CAPTIM randomized clinical trial. Circulation 2003; 108: 2851-6.

[17] Andersen HR, Nielsen TT, Rasmussen K, et al., for the DANAMI2 Investigators. A comparison of coronary angioplasty with fibrinolytic therapy in acute myocardial infarction. N Engl J Med 2003; 349: 733-42.

[18] Aversano T, Aversano LT, Passamani E, et al., for the Atlantic Cardiovascular Patient Outcomes Research Team (C-PORT). Thrombolytic therapy vs primary percutaneous coronary intervention for myocardial infarction in patients presenting to hospitals without on-site cardiac surgery: a randomized controlled trial. JAMA 2002; 287: 1943-51. 
[19] Ribeiro EE, Silva LA, Carneiro R, et al. Randomized trial of direct coronary angioplasty versus intravenous streptokinase in acute myocardial infarction. J Am Coll Cardiol 1993; 22: 376-80.

[20] Grinfeld L, Berrocal D, Bellardi J, et al. Fibrinolytics versus primary angioplasty in acute myocardial infarction (FAP): a randomized trial in a community hospital in Argentina. J Am Coll Cardiol 1996; 27: A222.

[21] Grines CL, Browne KF, Marco J, et al., for the Primary Angioplasty in Myocardial Infarction Study Group. Acomparison of immediate angioplasty with thrombolytic therapy for acute myocardial infarction. N Engl J Med 1993; 328: 673-9.

[22] Gibbons RJ, Holmes DR, Reeder GS, et al., for the Mayo Coronary Care Unit and Catheterization Laboratory Groups. Immediate angioplasty compared with the administration of a thrombolytic agent followed by conservative treatment for myocardial infarction. N Engl J Med 1993; 328: 685-91.

[23] Sabatine MS, Cannon CP, Gibson CM, et al., for the CLARITYTIMI 28 investigators. Addition of clopidogrel to aspirin and fibrinolytic therapy for myocardial infarction with ST-segment elevation. N Engl J Med 2005; 352: 1179-89.

[24] Chen ZM, Pan HC, Chen YP, et al. COMMIT (ClOpidogrel and Metoprolol in Myocardial Infarction Trial) collaborative group. Early intravenous then oral metoprolol in 45,852 patients with acute myocardial infarction: randomised placebo-controlled trial. Lancet 2005; 366: 1622-32.

[25] 2007 Focused Update of the ACC/AHA 2004 Guidelines for the Management of Patients With ST-Elevation Myocardial Infarction. J Am Coll Cardiol 2008; 51: 210-47.

[26] The Clopidogrel in Unstable Angina to Prevent Recurrent Events Trial Investigators. Effects of Clopidogrel in Addition to Aspirin in Patients with Acute Coronary Syndromes without ST-Segment Elevation. N Engl J Med 2001; 345: 494-502.

[27] The Scandinavian Simvastatin Survival group. Randomised trial of cholesterol lowering in 4444 patients with coronary heart disease: the Scandinavian Simvastatin Survival Study (4S). Lancet 1994; 344: $1383-9$.

[28] Sacks FM, Pfeffer MA, Moye LA, et al., for the Cholesterol and Recurrent Events Trial investigators. The effect of pravastatin on coronary events after myocardial infarction in patients with average cholesterol levels. N Engl J Med 1996; 335: 1001-9.

[29] The Long-Term Intervention with Pravastatin in Ischaemic Disease (LIPID) Study Group. Prevention of cardiovascular events and death with pravastatin in patients with coronary heart disease and a broad range of initial cholesterol levels. N Engl Med 1998; 339: 1349-57.
[30] Riegger G, Abletshauser C, Ludwig M, et al. The effect of fluvastatin on cardiac events in patients with symptomatic coronary artery disease during one year of treatment. Atherosclerosis 1999; 144: 263-70.

[31] Latini R, Maggioni AP, Flather M, Sleight P, Tognoni G. ACE inhibitor use in patients with myocardial infarction: summary of evidence from clinical trials. Circulation 1995; 92: 3132-7.

[32] Gruppo Italiano per lo Studio della Sopravvivenza nell'infarto Miocardico (GISSI). GISSI-3: effects of lisinopril and transdermal glyceryl trinitrate singly and together on 6-week mortality and ventricular function after acute myocardial infarction. Lancet 1994; 343: 1115-22.

[33] Ambrosioni E, Borghi C, Magnani B, for the Survival of Myocardial Infarction Long-Term Evaluation (SMILE) Study Investigators. The effect of the angiotensin-converting-enzyme inhibitor zofenopril on mortality and morbidity after anterior myocardial infarction. N Engl J Med 1995; 332: 80-5.

[34] Oral captopril versus placebo among 13,634 patients with suspected acute myocardial infarction: interim report from the Chinese Cardiac Study (CCS-1). Lancet 1995; 345: 686-7.

[35] Yusuf S, Sleight P, Pogue J, Bosch J, Davies R, Dagenais G, for the Heart Outcomes Prevention Evaluation Study Investigators. Effects of an angiotensin-converting-enzyme inhibitor, ramipril on cardiovascular events in high-risk patients. N Engl J Med 2000; 342: 145-53.

[36] Fibrinolytic Therapy Trialists' (FTT) Collaborative Group. Indications for fibrinolytic therapy in suspected acute myocardial infarction: collaborative overview of early mortality and major morbidity results from all randomised trials of more than 1000 patients. Lancet 1994; 343: 311-322.

[37] ISIS-4 (Fourth International Study of Infarct Survival) Collaborative Group. ISIS-4: A randomised factorial trial assessing early oral captopril, oral mononitrate, and intravenous magnesium sulphate in 58050 patients with suspected acute myocardial infarction. The Lancet 1995; 345: 669-82.

[38] Cannon CP, Braunwald E, Mc CabeCH, et al. Comparison of intensive and moderate lipid lowering with statins after acute coronary syndromes. N Engl J Med 2004; 350: 1562-4.

[39] The European trial On reduction of cardiac events with Perindopril in stable coronary Artery disease Investigators. Efficacy of perindopril in reduction of cardiovascular events among patients with stable coronary artery disease: randomised, double-blind, placebo-controlled, multicentre trial (the EUROPA study). Lancet 2003; 362: 782-8.

[40] Yusuf S. Two decades of progress in preventing vascular disease. Lancet 2002; 360: 2-3. 